Strahlenther Onkol 2014 • 190:546-554

DOI 10.1007/s00066-014-0628-y

Received: 3 October 2013

Accepted: 22 January 2014

Published online: 11 March 2014

(c) Springer-Verlag Berlin Heidelberg 2014

Laëtitia Lestrade ${ }^{1}$ Berardino De Bari ${ }^{2}$. Pascal Pommier ${ }^{1}$ Xavier Montbarbon ${ }^{1}$. Emilie Lavergne $^{3}$. Jean-Michel Ardiet ${ }^{4} \cdot$ Christian Carrie $^{1}$

${ }^{1}$ Radiation Oncology, Léon Bérard Cancer Center, Lyon, France

${ }^{2}$ Radiation Oncology, Centre hospitalier universitaire vaudois (CHUV), Lausanne, Switzerland

${ }^{3}$ Unité de Biostatistique et d'Evaluation des Thérapeutiques, Léon Bérard Cancer Center, Lyon, France

${ }^{4}$ Radiation Oncology, Centre Hospitalier Lyon Sud, Lyon, France

\title{
Role of brachytherapy in the treatment of cancers of the anal canal
}

\section{Long-term follow-up and multivariate analysis of a large monocentric retrospective series}

This study reports long-term (median

Anal canal cancers are rare, representing $2 \%$ of all digestive cancers and $6 \%$ of anorectal cancers, but their incidence is increasing [1]. External beam radiotherapy (EBRT), with concomitant chemotherapy (CT) for advanced tumors, is the standard treatment for anal canal carcinoma. Randomized controlled trials (RCTs) clearly assessed the role of concomitant CT in this setting [2-4]. The optimal dose and schedule of EBRT is still under investigation, but the importance of delivering a total dose of $\geq 55-59$ Gy to the tumor bed to patients with stage II/III anal canal cancer is supported by retrospective studies showing better local control rates at these dose levels [5, 6]. International guidelines support the utility of a boost after EBRT \pm CT [7]. Brachytherapy (BRT) is considered a valuable technique for delivering the boost to T1-T2 and selected small $\mathrm{T} 3$ anal tumors responding to EBRT $\pm \mathrm{CT}$ [8], but its role has not been evaluated extensively.

Indeed, the number of patients treated with BRT in the context of RCTs or in retrospective series is often limited; there are only three retrospective studies presenting results of more than 200 patients treated with BRT, with median follow-up times of 36-65 months [9-11]. follow-up, $>6$ years) data on the efficacy and toxicity in a large population of patients treated with EBRT \pm CT and BRT.

\section{Patients and methods}

\section{Study population and treatment}

We retrospectively reviewed the data of patients with histologically proven anal canal cancer treated with curative intent using EBRT $\pm \mathrm{CT}$ and a boost delivered using BRT, updating the follow-up of patients who had not been seen for more than 12 months leading up to the date of this analysis. Although the EBRT $\pm \mathrm{CT}$ treatment was delivered in different radiotherapy departments, all the BRT procedures were performed in the same radiotherapy department, ensuring the homogeneity of data with respect to BRT. The clinical stage of the tumors was defined according to the 2002 International Union Against Cancer Classification (UICC 2002) [12].

Primary endpoints were local control (LC) and acute and late toxicity rates. Overall (OS), cancer-specific (CSS), disease-free (DFS), colostomy-free, nodal relapse-free (NRFS), and metastasesfree survival (MFS) were secondary end- points. The impact of some clinical and therapeutic variables on the considered endpoints was also evaluated and reported (• Table 1).

\section{Statistical analysis}

The characteristics of the study population and the acute and late toxicity events are reported by descriptive statistics. We considered acute toxicity as those events recorded up to 6 months from the end of treatment, while all others were considered as late toxicities.

Acute and late toxicities were retrospectively scored with the NCI-CTC scale v. 4.0 [13], while sphincter function was evaluated by the Womack scale [13].

LC, NRFS, and MFS times were calculated from the end of BRT until the date of local, nodal (inguinal and/or pelvic), or metastatic disease recurrence, respectively (or the date of the last follow-up in disease-free patients). Any local, nodal, or systemic relapse was considered as an event in order to calculate the DFS rates.

OS and CSS were calculated from the date of the biopsy to the date of death from any cause or from cancer, respectively (or the date of the last follow-up, if alive). The Kaplan-Meier method was used to analyze these endpoints. 
Table 1 Primary (in italics) and secondary endpoints of the study and variables considered in the univariate and multivariate analysis

\begin{tabular}{|c|c|}
\hline Endpoints & Variables \\
\hline Local control (LC) & $\mathrm{T}(1-2$ vs. 3-4) \\
\hline Overall survival (OS) & $\mathrm{N}(0$ vs. $1-3)$ \\
\hline Cancer-specific survival (CSS) & Neoadjuvant CT (yes vs. no) \\
\hline Disease-free survival (PFS) & Concomitant CT (yes vs. no) \\
\hline Colostomy-free survival & Type of concomitant CT (5-FU/CDDP vs. 5-FU/MMC vs. other) \\
\hline Nodal-relapse free survival (NRFS) & Dose of pelvic RT ( $\leq 45$ Gy vs. $>45$ Gy) ${ }^{a}$ \\
\hline \multirow[t]{6}{*}{ Metastases-free survival (MFS) } & Response after $\mathrm{RT} \pm \mathrm{CT}(\leq 75 \%$ vs. $>75 \%)$ \\
\hline & Dose of BRT (<18 Gy vs. $\geq 18$ Gy) $)^{\mathrm{a}}$ \\
\hline & Total dose \\
\hline & LC (yes vs. no) \\
\hline & Inguinal RT (yes vs. no) \\
\hline & Pelvic volume (large vs. small) \\
\hline Acute toxicity rates & Smoking (yes vs. no) \\
\hline \multirow[t]{11}{*}{ Late toxicity rates } & Diabetes (yes vs. no) \\
\hline & Body mass index (BMI) \\
\hline & Concomitant CT (yes vs. no) \\
\hline & Dose of pelvic RT ( $\leq 45$ Gy vs. $>45$ Gy) ${ }^{a}$ \\
\hline & Pelvic volume (Large vs. small) \\
\hline & Total dose (<63 Gy vs. $\geq 63$ Gy) ${ }^{\mathrm{a}}$ \\
\hline & Dose of BRT (<18 Gy vs. $\geq 18$ Gy) ${ }^{\mathrm{a}}$ \\
\hline & Number of implants $(<6 \text { vs. } \geq 6)^{\mathrm{a}}$ \\
\hline & Length of sources (in cm) $(\leq 5 \mathrm{vs} .>5)^{\mathrm{a}}$ \\
\hline & Linear activity $(\mathrm{mCi} / \mathrm{cm})(\leq 1.19 \mathrm{vs} .>1.19)^{\mathrm{a}}$ \\
\hline & Dose rate of BRT $(G y / h)(<0.75 \text { vs. } \geq 0.75)^{\mathrm{a}}$ \\
\hline \multicolumn{2}{|c|}{$\begin{array}{l}\text { CT chemotherapy, RT radiotherapy, BRT brachytherapy, LC Local control, 5-FU 5-fluorouracil, CDDP cisplatin, } \\
\text { MMC mitomycin C } \\
\text { aFor these variables, median values were chosen to identify the subgroups }\end{array}$} \\
\hline
\end{tabular}

- Table 1 summarizes the clinical and therapeutic features (selected from the available literature) studied in the univariate analysis (performed by the logrank test). Multivariate analysis was performed using the Cox regression test. A $p$ value less than 0.05 was considered statistically significant. Statistical analysis was performed using the SPSS software (SPSS Statistics 17.0@, 1993-2007).

\section{Results}

\section{Patient and tumor characteristics}

Between May 1992 and November 2009, a total of 234 patients were referred to the Radiation Oncology Department of the study center to be treated with BRT. Fifteen patients who received exclusive BRT and ten patients who were lost to followup after BRT were excluded from this analysis; thus, the data of 209 patients are presented. The median follow-up for the whole population was 72.8 months.

- Table 2 summarizes the patient characteristics.

\section{Staging procedures and tumor stage}

All patients underwent a pretreatment physical examination, chest radiography, ultrasonography of the abdomen, routine laboratory tests, and tumor biopsy.

Abdominal computed tomography scan, magnetic resonance imaging (MRI), and, more recently, endorectal ultrasound (EUS) were also performed according to the treatment period ( $\bullet$ Table 2$)$.

We found that 85 patients $(41 \%)$ had a locally advanced tumor (T3-T4), while synchronous pelvic and/or inguinal lymph node metastases were observed in 58 patients $(27 \%)$. The total number of patients with T3 and T4 cancer was 80

\begin{tabular}{|c|c|c|}
\hline & Number & Percentage \\
\hline Patients $(n)$ & 219 & $100 \%$ \\
\hline \multicolumn{3}{|l|}{ Sex } \\
\hline Male & 36 & $16.44 \%$ \\
\hline Female & 183 & $83.56 \%$ \\
\hline \multicolumn{3}{|l|}{ Age (years) } \\
\hline Mean & 63.4 & \\
\hline Median (range) & $64(25-88)$ & \\
\hline \multicolumn{3}{|c|}{ Performance status } \\
\hline 0 & 173 & $79 \%$ \\
\hline 1 & 46 & $21 \%$ \\
\hline \multicolumn{3}{|l|}{ Tobacco } \\
\hline Yes (stopped) & $20(10)$ & $9.5 \%(4.8 \%)$ \\
\hline No & 185 & $88.5 \%$ \\
\hline Not available & 4 & $2 \%$ \\
\hline \multicolumn{3}{|c|}{ Quantity in PA (packets/year) } \\
\hline Median & 25 & \\
\hline Range & $(1-60)$ & \\
\hline $\begin{array}{l}\text { Diabetes under } \\
\text { treatment }\end{array}$ & 10 & \\
\hline Type 1 & 8 & \\
\hline Type 2 & 1 & \\
\hline $\begin{array}{l}\text { Type } 2 \text { needing } \\
\text { insulin }\end{array}$ & 1 & \\
\hline \multicolumn{3}{|c|}{ Body mass index $\mathrm{kg} / \mathrm{m}^{2}$} \\
\hline$<25$ & 120 & \\
\hline$\geq 25$ & 65 & \\
\hline Not available & 44 & \\
\hline HIV infection & 5 & \\
\hline \multicolumn{3}{|l|}{ Symptoms } \\
\hline Any & 7 & $3.4 \%$ \\
\hline Rectal bleeding & 119 & $57.5 \%$ \\
\hline Pain & 71 & $34.3 \%$ \\
\hline $\begin{array}{l}\text { Mass/ } \\
\text { hemorrhoids }\end{array}$ & 51 & $24.6 \%$ \\
\hline Inguinal nodes & 8 & $3.9 \%$ \\
\hline Rectal syndrome & 27 & $13.0 \%$ \\
\hline $\begin{array}{l}\text { Fecal transit } \\
\text { problems }\end{array}$ & 25 & $12.1 \%$ \\
\hline Other & 12 & $5.8 \%$ \\
\hline $\begin{array}{l}\text { Endorectal } \\
\text { echography }\end{array}$ & 136 & $66 \%$ \\
\hline $\begin{array}{l}\text { Magnetic reso- } \\
\text { nance imaging }\end{array}$ & 48 & $23.3 \%$ \\
\hline
\end{tabular}

and 5, respectively. In particular, among the $\mathrm{T} 4$ group, three were referred to BRT because of a major response after the radiochemotherapy (RT-CT) and two of them refused surgery. $\bullet$ Table 3 summarizes the disease characteristics. 


\section{External beam radiotherapy}

All patients underwent EBRT to the anal canal and pelvic nodal areas. This was delivered with different techniques of irradiation according to the year of the treatment and the internal protocols of the treating centers (- Table 4 ). The median dose to this volume was $45 \mathrm{~Gy}$ (range, $30-56$ ), with a median dose/fraction of 1.8 Gy (range, 1.8-3). Only nine patients received hypofractionated EBRT ( $3 \mathrm{~Gy} /$ fraction), to a median dose of $39 \mathrm{~Gy}$ (range, 36-39).

Patients presenting with a more advanced $\mathrm{T}$ stage (i.e., T3 and T4) received a median dose of BRT of 18 Gy (range, 10-22), not statistically different from the rest of the patients. Regarding the technical aspects of the implants of patients with T4 disease, one, two, one, and one patients needed five, six, seven, or eight needles, respectively. Concerning the clinical outcomes, 40 of 80 category-T3 patients and three of five category-T4 patients showed a response of greater than $75 \%$ after the first course of RT-CT. Finally, 17 of 80 category-T3 patients and one offive category-T4 patients received a colostomy for locally relapsing or residual disease. Among these 18 patients, 11 had a response of greater than $75 \%$ and seven had a response of less than $75 \%$.

Median overall treatment time for EBRT \pm CT was 36 days (range, 15-74).

Inguinal irradiation was delivered with a prophylactic (24 patients) or curative intent (19 patients). The median dose was 46 Gy (range, 7-60) and 45 Gy (range, 41.4-60) in the curative and in the prophylactic setting, respectively.

\section{Brachytherapy}

EBRT was always followed by a BRT boost using ${ }^{192}$ Ir sources, delivered with a lowdose rate (LDR, 151 patients) or a pulsedose rate (PDR, 58 patients) depending on the availability of the technique in the department (• Table 4). BRT was performed following the technique described by Papillon [9], following the system of Paris for the dosimetry, and prescribing the dose to the isodose of $85 \%$ of the prescribed dos. The median dose

Strahlenther Onkol 2014 · 190:546-554 DOI 10.1007/s00066-014-0628-y

(c) Springer-Verlag Berlin Heidelberg 2014

\section{Lestrade · B. De Bari · P. Pommier · X. Montbarbon · E. Lavergne · J.-M. Ardiet · C. Carrie Role of brachytherapy in the treatment of cancers of the anal canal. Long-term follow-up and multivariate analysis of a large monocentric retrospective series}

\section{Abstract}

Background and purpose. There are few data on long-term clinical results and tolerance of brachytherapy in anal canal cancer. We present one of the largest retrospective analyses of anal canal cancers treated with external beam radiotherapy with/without $( \pm)$ chemotherapy followed by a brachytherapy boost.

Materials and methods. We performed a retrospective analysis of clinical results in terms of efficacy and toxicity. The impact of different clinical and therapeutic variables on these outcomes was studied.

Results. From May 1992 to December 2009, 209 patients received brachytherapy after external beam radiotherapy \pm chemotherapy. Of these patients, 163 were stage II or stage IIIA (UICC 2002) and 58 were N1-3. According to age, ECOG performance status (PS), and comorbidities, patients received either radiotherapy alone $(58 / 209)$ or radiochemo- therapy (151/209). The median follow-up was 72.8 months. The 5 - and 10-year local control rates were 78.6 and $73.9 \%$, respectively. Globally, severe acute and late G3-4 reactions (NCI-CTC scale v. 4.0) occurred in 11.2 and $6.3 \%$ of patients, respectively. Univariate analysis showed the statistical impact of the pelvic treatment volume $(p=0.046)$ and of the total dose $(p=0.02)$ on the risk of severe acute and late toxicities, respectively. Only six patients required permanent colostomy because of severe late anorectal toxicities. Conclusion. After a long follow-up time, brachytherapy showed an acceptable toxicity profile and high local control rates in patients with anal canal cancer.

Keywords

Anal canal cancer · Radiotherapy .

Brachytherapy $\cdot$ Toxicity $\cdot$ Local control

\section{Stellenwert der Brachytherapie bei der Behandlung von Tumoren des Analkanals. Langzeit-Follow-up und multivariate Analyse einer großen monozentrischen, retrospektiven Studie}

\section{Zusammenfassung}

Hintergrund und Ziel. Es gibt gegenwärtig nur wenige klinische Daten zu den Ergebnissen und Nebenwirkungen von Brachytherapie bei Analkanaltumoren. Wir präsentieren die Daten einer der größten retrospektiven Auswertungen für die Behandlung von Analkanaltumoren mit perkutaner Radiotherapie \pm simultaner Chemotherapie, gefolgt von einem Brachytherapie-Boost.

Material und Methoden. Wir analysierten retrospektiv die Patientendaten hinsichtlich Toxizität und Tumorkontrolle. Der Einfluss verschiedener klinischer und therapeutischer Variablen auf das Outcome der Patienten wurde untersucht.

Ergebnisse. Zwischen Mai 1992 und Dezember 2009 erhielten 209 Patienten eine Brachytherapie nach perkutaner Strahlentherapie \pm simultaner Chemotherapie. Hiervon waren 163 Patienten Stadium II oder IIIA (UICC 2002) und 58 N1-3. Entsprechend ihres Alters, ECOG-Status und Komorbiditäten erhielten die Patienten entweder eine alleinige Strahlentherapie (58/209) oder eine kombinierte
Radiochemotherapie (151/209). Die mediane Nachbeobachtungszeit lag bei 72,8 Monaten. Die lokale Kontrolle nach 5 bzw. 10 Jahren lag bei $78,6 \%$ bzw. 73,9\%. Schwere akute bzw. chronische Therapienebenwirkungen (G3-G4 nach NCI-CTC-Scale v. 4.0) traten in 11,2\% bzw. 6,3\% der Fälle auf. Univariate Analysen zeigten einen Einfluss des pelvinen Bestrahlungsvolumens $(p=0,046)$ und der Gesamt$\operatorname{dosis}(p=0,02)$ für das Risiko, schwerwiegende akute oder chronische Nebenwirkungen zu entwickeln. Lediglich 6/209 Patienten benötigten die Anlage eines dauerhaften Kolostomas aufgrund schwerwiegender anorektaler Toxizitäten.

Schlussfolgerung. Nach langer Nachsorgezeit zeigte die Brachytherapie bei Analkanaltumoren ein akzeptables Nebenwirkungsprofil bei hoher lokaler Kontrolle.

\section{Schlüsselwörter}

Analkanaltumor · Radiotherapie .

Brachytherapie · Toxizität · Lokale Kontrolle 
Table 3 Disease characteristics

Patients \%

(n)

\begin{tabular}{|lll}
\hline Location & & \\
\hline Anal canal & 106 & 50.7 \\
\hline $\begin{array}{l}\text { Anal canal reaching anal } \\
\text { margin }\end{array}$ & 41 & 19.6 \\
\hline Rectoanal area & 55 & 26.3 \\
\hline Anal margin & 2 & 1.0 \\
\hline $\begin{array}{l}\text { Anal canal, anal margin, } \\
\text { and rectum }\end{array}$ & 2 & 1.0 \\
\hline Not available & 3 & 1.4 \\
\hline Tumor & & \\
\hline T1 & 26 & 12.4 \\
\hline T2 & 98 & 46.9 \\
\hline T3 & 80 & 38.3 \\
\hline T4 & 5 & 2.4 \\
\hline
\end{tabular}

Not available

\section{Histologic grade distribution}

\begin{tabular}{lll}
\hline Carcinoma in situ & 4 & 1.9 \\
\hline $\begin{array}{l}\text { Large-cell keratinizing } \\
\text { squamous cell carcinoma }\end{array}$ & 56 & $26.8 \%$ \\
\hline $\begin{array}{l}\text { Non-keratinizing squa- } \\
\text { mous cell carcinoma }\end{array}$ & 120 & $57.4 \%$ \\
\hline $\begin{array}{l}\text { Basaloid squamous cell } \\
\text { carcinoma }\end{array}$ & 17 & 8.1 \\
\hline $\begin{array}{l}\text { Adenocarcinoma of } \\
\text { rectal—anal glands type }\end{array}$ & 5 & 2.4 \\
\hline \begin{tabular}{l} 
Carcinoma with small cells \\
\hline $\begin{array}{l}\text { Undifferentiated carci- } \\
\text { noma }\end{array}$
\end{tabular} & 1 & 0.5 \\
\hline
\end{tabular}

Other tumors (sarco- $\quad 1 \quad 0.5$

mas-lymphomas-

melanomas)

\begin{tabular}{lll}
\hline Cloacogenic & 3 & 1.4 \\
\hline Not available & 1 & 0.5 \\
\hline HPV & 11 & 5.2 \\
\hline
\end{tabular}

\begin{tabular}{lll} 
Nodal status & & \\
\hline N0 & 151 & 72.3 \\
\hline N1 & 36 & 17.2 \\
\hline N2 & 15 & 7.2 \\
\hline N3 & 7 & 3.3 \\
\hline
\end{tabular}

\section{Staging TNM}

\begin{tabular}{lll}
\hline I & 22 & 10.5 \\
\hline II & 125 & 59.8 \\
\hline IIIA & 38 & 18.2 \\
\hline IIIB & 24 & 11.5 \\
\hline
\end{tabular}

Histological procedures

\begin{tabular}{lll}
\hline Biopsy only & 194 & 92.8 \\
\hline Surgical margin R0 & 4 & 1.9 \\
\hline Surgical margin R1 & 6 & 2.9 \\
\hline Surgical margin R2 & 5 & 2.4 \\
\hline $\begin{array}{l}\text { Squamous cell carcinoma } \\
\text { antigen (median value } \\
\text { and range) }\end{array}$ & $\begin{array}{l}1.95 \mathrm{ng} / \mathrm{ml} \\
(0-11.7)\end{array}$ \\
\hline $\begin{array}{l}\text { aAvailable for only 17 patients } \\
\end{array}$ & & \\
\hline
\end{tabular}

Table 4 Radiotherapy and chemotherapy External beam radiation therapy (EBRT)

Treating center (patients)

\begin{tabular}{|lll}
\hline Current study center & 78 & $37.3 \%$ \\
\hline Others & 131 & $62.7 \%$ \\
\hline Decubitus (patients) & & \\
\hline Ventral & 9 & $4.3 \%$ \\
\hline Dorsal & 200 & $95.7 \%$ \\
\hline Total dose (Gy) & & \\
\hline Median (range) & $45(36-56)$ & \\
\hline $\begin{array}{l}\text { Median dose/fraction } \\
\text { (range) }\end{array}$ & $1.8(1.8-3)$ & \\
\hline Pelvic & & \\
\hline
\end{tabular}

Pelvic volume (patients)

"Small pelvis" (upper $165 \quad$ 79.0\%
border up to S3)

"Large pelvis" (upper $41 \quad 19.6 \%$

border up to L5)

Not available $\quad 3 \quad 1.4 \%$

Inguinal irradiation (patients)

\begin{tabular}{lll} 
No & 161 & $77.0 \%$ \\
\hline Unilateral & 6 & $2.9 \%$
\end{tabular}

Bilateral $\quad 42 \quad 20.1 \%$

Type of beams (patients)

\begin{tabular}{lll} 
Photons & 201 & $96.2 \%$ \\
\hline $\begin{array}{l}\text { Photons + perineal } \\
\text { field (electrons) }\end{array}$ & 4 & $1.9 \%$ \\
${ }^{60}$ Cobalt & 4 & $1.9 \%$
\end{tabular}

\begin{tabular}{lcc}
${ }^{60}$ Cobalt & 4 & $1.9 \%$ \\
\hline
\end{tabular}

Field arrangement (patients)

Orthogonal fields $\quad 159 \quad 76 \%$

(2-4 fields)

Direct perineal fields $38 \quad 18.3 \%$

+ orthogonal fields

(2-4 fields)

Intensity modulated $4 \quad 1.9 \%$

radiation therapy

\begin{tabular}{lll}
\hline Not available & 8 & $3.8 \%$ \\
\hline $\begin{array}{l}\text { Median number of } \\
\text { fractions (range) }\end{array}$ & $25(12-28)$ \\
\hline $\begin{array}{l}\text { RT duration in days } \\
\text { (range) }\end{array}$ & $36(15-74)$ \\
\hline
\end{tabular}

\section{Brachytherapy (BRT)}

Median interval be- 32 (12-151) tween EBRT and BRT in days (range)

\section{BRT technique (patients)}

\begin{tabular}{lll}
\hline Low-dose rate & 151 & $72.2 \%$ \\
\hline Pulsed-dose rate & 58 & $27.8 \%$ \\
\hline Median dose (range) & $18(10-31.7)$ \\
\hline $\begin{array}{l}\text { Median duration of } \\
\text { BRT in hours (range) }\end{array}$ & $22(11-77)$ \\
\hline $\begin{array}{l}\text { Linear activity (mCi/ } \\
\text { cm, range) }\end{array}$ & 1.19 \\
\hline $\begin{array}{l}\text { Dose rate (Gy/h, } \\
\text { range) }\end{array}$ & $\begin{array}{l}0.75 \\
(0.23-1.25)\end{array}$ \\
\hline $\begin{array}{l}\text { Number of sources } \\
\text { (range) }\end{array}$ & $6(4-12)$ \\
\hline
\end{tabular}

Table 4 continued

External beam radiation therapy (EBRT)

Median length of $\quad 5(4-9)$

sources ( $\mathrm{cm}$, range)

Median total

dose EBRT + BRT

(Gy, range)

Concomitant chemotherapy

Schedule (patients)

During the $1^{\text {st }}$ week $\quad 18 \quad 11.9 \%$

of EBRT

During the $1^{\text {st }}$ and $5^{\text {th }} \quad 123 \quad 81.5 \%$ week of EBRT

\begin{tabular}{lll}
\hline Weekly & 10 & $6.6 \%$ \\
\hline \multicolumn{3}{l}{ Chemotherapy protocol } \\
\hline 5FU-CDDP & 104 & $68.9 \%$ \\
\hline 5FU-MMC & 31 & $20.5 \%$ \\
\hline Weekly CDDP 40 mg & 6 & $4 \%$ \\
\hline Weekly carboplatin & 3 & $1.9 \%$ \\
\hline 5FU-carboplatin & 3 & $1.9 \%$ \\
\hline Weekly CDDP 30 mg & 1 & $0.7 \%$ \\
\hline 5FU-leucovorin & 1 & $0.7 \%$ \\
\hline Xeloda-MMC & 1 & $0.7 \%$ \\
\hline $\begin{array}{l}\text { Weekly MMC } \\
\text { 5-FU 5-fluorouracil, CDDP cisplatin, MMC mito- } \\
\text { mycin C }\end{array}$ & \multicolumn{3}{l}{} \\
\hline
\end{tabular}

was $18 \mathrm{~Gy}$ (range, 10-31.7). The median time of application was $22 \mathrm{~h}$ (range, 1177 ), and the median interval between the end of EBRT $\pm \mathrm{CT}$ and BRT was 32 days (range, 12-151).

\section{Chemotherapy}

Eighteen patients received neoadjuvant $\mathrm{CT}$, and CDDP $+5-\mathrm{FU}$ was given to 17 of 18 patients. Because of renal toxicity after the first cycle of $\mathrm{CT}$, one patient received carboplatin AUC5 instead of CDDP during the last cycle.

Concomitant CT was delivered to 151 patients, most of whom $(89 \%)$ received $\mathrm{CDDP}+5-\mathrm{FU}(69 \%)$ or $5-\mathrm{FU}+\mathrm{MMC}$ $(20 \%)$. Table 4 summarizes the data for concomitant CT.

\section{Clinical results: primary endpoints}

\section{Local control}

Clinical response after the EBRT was evaluated by digital rectal examination (DRE) with the patient under general anesthesia just before the BRT procedure; this information was available for 198 of 209 patients. Response was rated as less than 


\begin{tabular}{lllll}
\hline Table $\mathbf{5}$ & Acute and late toxicity & & Late toxicity \\
& Acute toxicity & & Grade 1-2 & Grade 3-4 \\
\hline & Grade 1-2 & Grade $\mathbf{3}$ & 6 & 0 \\
\hline Skin & 102 & 12 & 19 & 0 \\
\hline Diarrhea & 138 & 3 & 64 & 10 \\
\hline Anal & 132 & 8 & 78 & 4 \\
\hline Rectal & 39 & 1 & 0 & 0 \\
\hline Vulvar & 15 & 2 & 8 & 0 \\
\hline Vaginal & 12 & 1 & 5 & 0 \\
\hline Urinary & 18 & 1 & &
\end{tabular}

Table 6 Clinical outcomes with results of univariate and multivariate analysis

\begin{tabular}{|llllllll}
\hline & $\begin{array}{l}5 \text {-year } \\
\text { LC }\end{array}$ & $\begin{array}{l}\text { 5-year } \\
\text { OS }\end{array}$ & $\begin{array}{l}\text { 5-year } \\
\text { CSS }\end{array}$ & $\begin{array}{l}\text { 5-year } \\
\text { DFS }\end{array}$ & $\begin{array}{l}\text { 5-year } \\
\text { CFS }\end{array}$ & $\begin{array}{l}\text { 5-years } \\
\text { NRFS }\end{array}$ & $\begin{array}{l}\text { 5-years } \\
\text { MFS }\end{array}$ \\
\hline Overall population (\%) & 78.6 & 80.9 & 85.7 & 69.4 & 79.4 & 82.1 & 90.5 \\
\hline T & & & & & & & \\
\hline T1-T2 (\%) & 79.6 & 84.9 & 88.6 & 70.1 & 80.5 & 87.4 & 94.8 \\
\hline T3-T4 & 77.3 & 75.9 & 82.0 & 68.4 & 77.7 & 74.6 & 84.7 \\
\hline$p$ & 0.5 & 0.13 & 0.14 & 0.94 & 0.50 & 0.006 & 0.08 \\
\hline Neoadjuvant CT & & & & & & & \\
\hline Yes(\%) & 81.6 & 74.9 & 79.3 & 69.0 & 82.4 & 88.5 & 76.7 \\
\hline No (\%) & 78.9 & 82.0 & 86.2 & 72.2 & 79.6 & 81.5 & 91.8 \\
\hline$p$ & 0.85 & 0.91 & 0.69 & 0.71 & 0.79 & 0.46 & 0.047 \\
\hline Concomitant CT & & & & & & & \\
\hline Yes (\%) & 80.3 & 84.7 & 88.8 & 76.7 & 80.6 & 81.5 & 91.4 \\
\hline No (\%) & 74.0 & 70.6 & 77.2 & 67.1 & 75.6 & 84.1 & 87.6 \\
\hline$p$ & 0.16 & 0.026 & 0.011 & 0.54 & 0.22 & 0.72 & 0.15 \\
\hline LC & - & & & - & & & \\
\hline Yes (\%) & & 89.5 & 94.7 & & 96.1 & 90.9 & 96.1 \\
\hline No (\%) & & 51.8 & 55.4 & & 19.8 & 51.3 & 70.6 \\
\hline$p$ & & $<0.0001$ & $<0.0001$ & & $<0.001$ & $<0.0001$ & $<0.0001$ \\
\hline BRT dose & & & & & & \\
\hline$<18$ Gy (\%) & 88.8 & 91.4 & 92.5 & 68.2 & 88.5 & 88.0 & 94.9 \\
\hline$\geq 18$ Gy (\%) & 72.2 & 74.7 & 81.5 & 69.7 & 73.6 & 78.4 & 87.8 \\
\hline$p$ & 0.003 & 0.045 & 0.047 & 0.37 & 0.002 & 0.09 & 0.08 \\
\hline LC & & & & & & & \\
\hline
\end{tabular}

LC local control, OS overall survival, CSS cancer-specific survival, DFS disease-free survival, CFS colostomy-free survival, NRFS nodal relapse-free survival, MFS metastases-free survival, CT chemotherapy, BRT brachytherapy

$25 \%$ in two patients, between 25 and $50 \%$ in 16 patients, between 50 and $75 \%$ in 78 patients, and $75 \%$ or greater in 102 patients.

Median LC time was not reached, with 5- and 10-year LC rates of 78.6 and 73.9\%, respectively (• Fig. 1). $\bullet$ Figure 1 shows the impact of LC on the considered secondary endpoints.

\section{Toxicity}

Data on toxicity were available for 205 of 209 patients. The global rates of G3-G4 acute and late toxicity were $11.2 \%$ and $6.3 \%$, respectively (• Table 5 ).
Of the 209 patients, 44 (21\%) underwent colostomy, 38 because of a local relapse and six to treat a G4 anorectal toxicity. Five- and 10-year CFS rates were 79.4 and $75.5 \%$, respectively.

Two of the nine patients treated with the hypofractionated schedule presented with a G3 acute toxicity (one with anal toxicity and the other with cutaneous toxicity) and none of them presented with G3-G4 late toxicity.

Sphincter function was evaluated in the remaining 165 patients and classified with the Womack scale [14] as score A (total continence) in 135 patients (82\%), score B (incontinence to gas) in 25 pa- tients (15\%), and score C (incontinence to liquid stools) in five patients (3\%).

Grade 3 chemotherapy-related acute toxicities were recorded in seven of 151 patients $(4.6 \%)$, with four patients presenting with CDDP-related renal toxicity, and three patients presenting with neutropenia, 5-FU-related cardiac toxicity, or gastrointestinal toxicity, respectively. No G4 acute toxicity was recorded. Treatment was interrupted ( $>7$ days) in only two patients and no patient failed to complete EBRT $\pm \mathrm{CT}$.

\section{Clinical results: secondary endpoints}

\section{Survival rates}

- Table 6 shows the 5-year OS, CSS, DFS, NRFS, and MFS rates (median, not reached).

The 10-year OS, CSS, DFS, NRFS, and MFS rates were $65.7,81,49.4,78.5$, and $88.8 \%$, respectively.

\section{Clinical results: univariate and multivariate analysis}

Regarding the impact of the variables on the primary endpoints ( $\bullet$ Table 6 ), BRT dose influenced LC, with lower doses showing better outcomes $(p=0.003)$. It should be noted that there was a statistical relationship between the total BRT dose (<18 Gy vs. $>18$ Gy) and objective response at clinical evaluation by DRE before BRT, with higher doses delivered to patients showing worse response $(p=0.001)$. LC statistically influenced all the considered endpoints $(p<0.001)$. - Figure 2 shows the impact of the BRT dose onthe secondary endpoints considered.

Multivariate analysis confirmed the statistical impact of concomitant CT on OS (HR: $0.55,95 \%$ CI $0.3-0.99, p=0.008$ ) and of LC on OS (HR: $0.25,95 \%$ CI $0.14-$ $0.45, p<0.001$ ) and on CSS (HR: 0.09, 95\% CI 0.04-0.21, $p<0.001$ ).

A total dose higher than the median total dose was the only variable that significantly influenced the risk of developing severe late toxicity, with rates of 2.7 and $10 \%$ for doses of $\leq 63$ Gy or $>63$ Gy $(p=0.02)$, respectively. The global incidence of G1-G4 severe toxicity was 


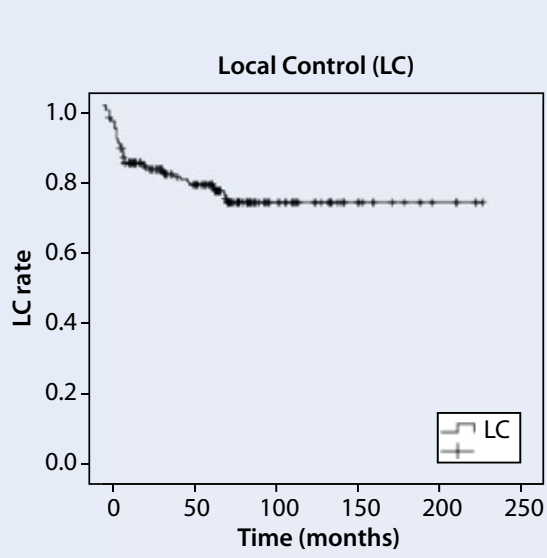

Local Control (LC) according to Brachytherapy dose $(<18$ Gy vs $>$ or $=18 \mathrm{~Gy})$

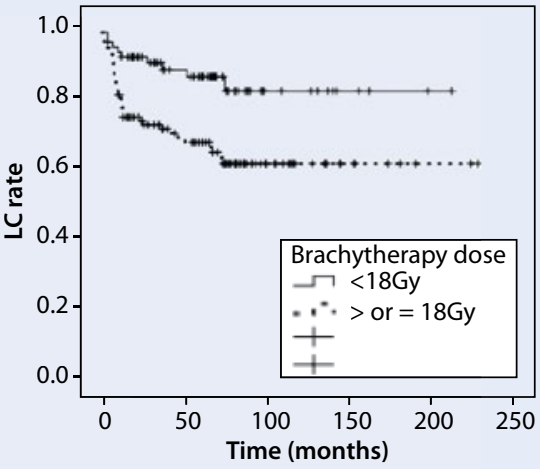

Overall Survival (OS) according to the Local Control

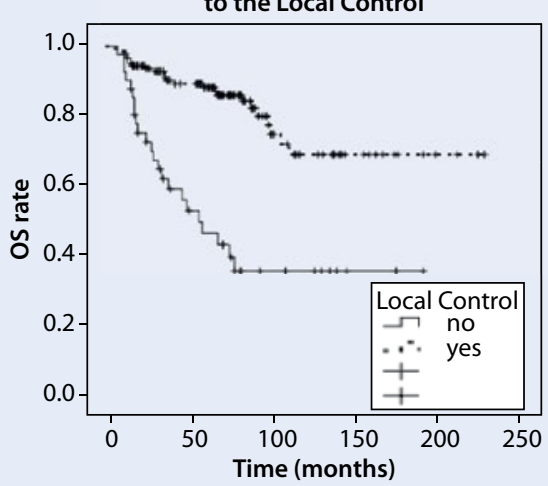

Cancer Specific Survival (CSS) according to Local Control

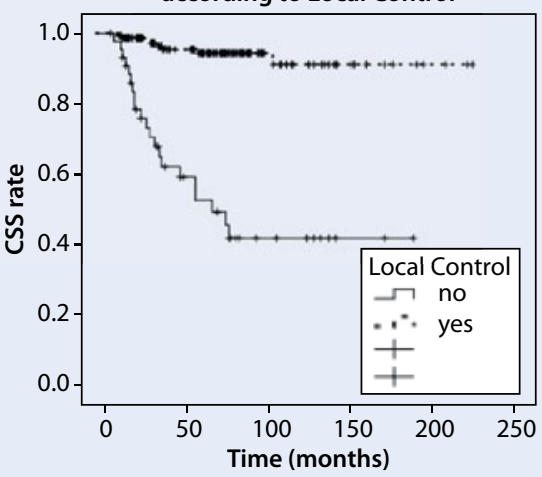

Fig. $1 \Delta$ Local control $(L C)$ and significant impact of $L C$ on some of the secondary endpoints considered (all $p<0.001$ )

influenced by the number of sources used ( $\geq 6$ vs. $<6,71.5$ vs. $56.2 \%, p=0.014$ ). Finally, a strong relationship was seen between pelvic volume and pelvic dose levels and the risk of late severe toxicity, but it was not significant $(p=0.05)$.

None of the other variables influenced the primary and secondary endpoints considered in this study and are therefore not reported in $\bullet$ Table 6 .

\section{Discussion}

BRT is an important therapeutic option in the treatment of anal canal cancers, but its role has not been evaluated extensively [8]. We report the long-term efficacy and safety data in a large population of more than 200 patients treated with EBRT $\pm \mathrm{CT}$ and BRT, with the longest median follow-up of 72.8 months. To date, only three retrospective studies enrolled more than 200 patients treated with BRT: Papillon et al. (221 patients and $>36$ months of follow-up), Chapet et al. (218 patients,
58 months of follow-up), and TournierRangeard et al. (233 patients, 65 months of median follow-up) [9-11]. Only a few patients enrolled in RCTs on anal canal cancer were treated with BRT [2-4].

Despite its retrospective nature and some biases inherent to the data collection on the EBRT \pm CT course (especially for the toxicity reporting), this study is of interest for several reasons.

Firstly, in the last two decades, therapeutic innovations introduced into the daily clinical practice of radiation oncologists (such as neoadjuvant/concomitant/adjuvant CT schedules, the rapid evolution of EBRT from 2D-EBRT to 3D-EBRT and, more recently, to different promising IMRT techniques) radically changed the approach to managing anorectal cancer patients $[7,15,16]$. Although there is good evidence on the efficacy of concomitant CT in the treatment of locally advanced anal canal cancers [7, 17] and in recent retrospective reports on the treatment of localized tumors [18] and in particular populations of patients, such as elderly or HIV-positive patients [19, 20, 21], the clinical meaning of the dosimetric advantages of these technical innovations must still be prospectively evaluated in terms of efficacy and toxicity, in the context of a Health Technology Assessment [22], as was recently stated by the European Society of Radiotherapy and Oncology [23]. Considering the difficulties in obtaining the same high-level evidence by RCTs and the potential selection bias, these trials do not represent "real-life" conditions. For these reasons, benchmark data are strongly needed when adopting other types of perspective evaluation of different treatment techniques and modalities, particularly for rare cancers like anal canal cancer.

Moreover, it is difficult to obtain historical data for BRT in anal canal cancer, as it is not widely performed. Last but not least, considering the potential impact of the experience on the efficacy and safety of BRT procedure, it is important to accumulate evidence in high-volume radiotherapy centers, assessing and confirming clinical results over a long period of follow-up.

In this context, our 5-year LC rate of $78.6 \%$ is comparable to the results of the three RCTs (ranging between 68 and $87 \%$ ) and to those of Tournier-Rangeard et al. (80.8\%) and of Papillon et al. (80\%, published in 1989) $[9,11]$. Chapet et al. did not give 5-year LC rates, as they only reported data for 5-year CFS (61.5\%) and DFS (60\%) rates [10]. Our results confirm the efficacy and the safety of BRT. The large number of patients and the long follow-up make our series one of the most important benchmark datasets in this clinical and therapeutic setting.

Univariate analysis indirectly supports the prognostic role of the clinical response after EBRT \pm CT reported by Wagner et al. and Peiffert et al., who suggested that lower doses of BRT could be delivered if there is complete response after EBRT \pm CT $[24,25]$. In our analysis, there was a statistical relationship between the total BRT dose (<18 Gy vs. >18 Gy) and clinical response at clinical evaluation by DRE before BRT, with higher doses delivered to patients showing worse response $(p=0.001)$, but also with lower doses showing better outcomes $(p=0.003)$. 

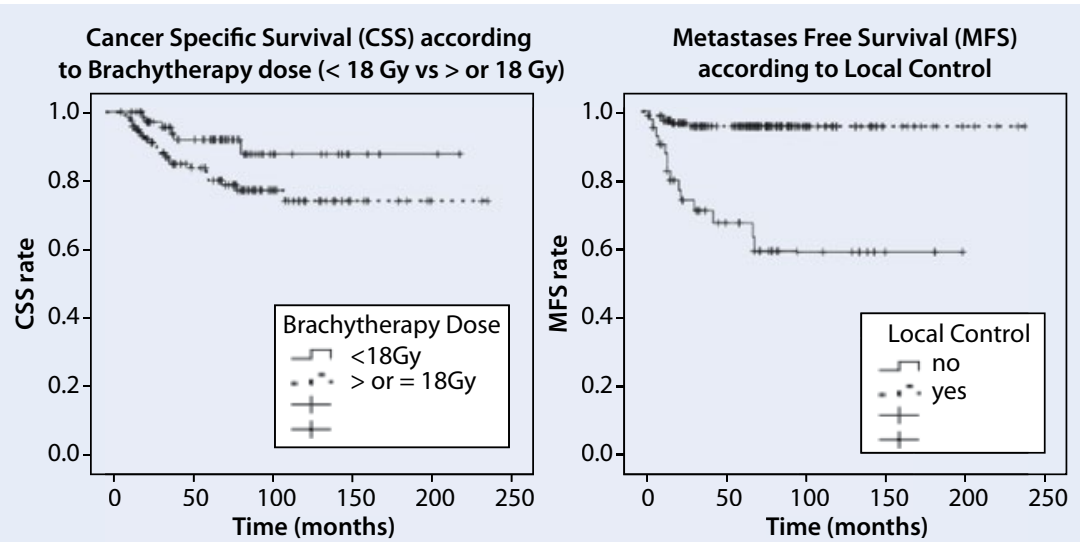

Colostomy Free Survival (CFS) according to Brachytherapy dose $(<18$ Gy vs $>$ or $=18 \mathrm{~Gy})$

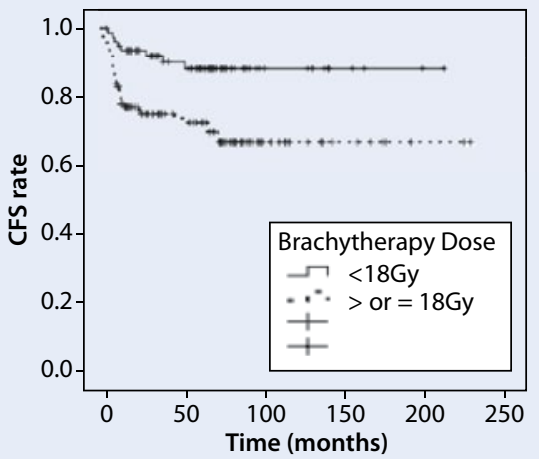

Overall Survival (OS) according to the Brachytherapy dose $(<18$ Gy vs $>$ or $=18 \mathrm{~Gy})$

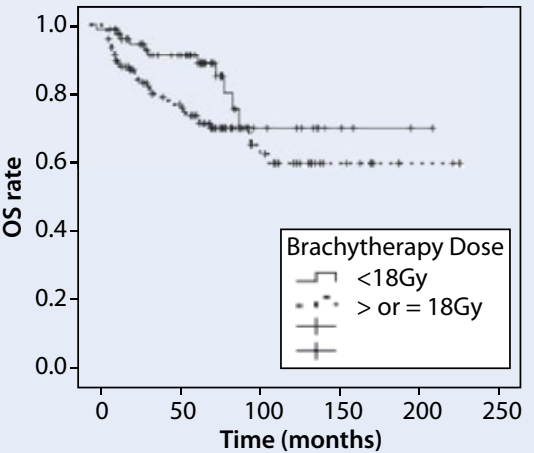

Fig. $2 \Delta$ Significant impact of the dose of brachytherapy on some of the secondary endpoints considered (all $p \leq 0.04$ )

Moreover, it should be noted that the risk of late toxicity was influenced by the total dose of EBRT and the number of implants, typically both larger in poorly responding patients.

These results could be interpreted as a potential limit of BRT, i.e., that BRT cannot compensate for a poor response to $\mathrm{EBRT} \pm \mathrm{CT}$, even using higher doses, and moreover could be more toxic in poorly responding patients.

In contrast to the published literature reporting the impact of $\mathrm{T}$ and $\mathrm{N}$ stage [4] and/or time between the end of EBRT \pm CT and boost [26] and/or tumor response before BRT [10] and/or total dose of EBRT [27, 28], none of the other studied clinical and therapeutic variables statistically influenced LC on multivariate analysis. The decision to use the median values (when indicated) as cut-offs in analyzing some of these variables (• Table 1 ) in order to have equally represented populations could explain these differences with the literature. We cannot exclude that different cut-offs would yield different statis- tical results, but we considered the choice of the median values a more "objective" way to distribute our population.

This study is also an important benchmark showing the safety of BRT with rates of 11.2 and $6.2 \%$ of acute and late severe toxicity, respectively. Published RCTs showed $54-74 \%$ of G3-G4 nonhematologic acute toxicity and $11-36 \%$ of G3-G4 nonhematologic late toxicity [24]. It should be noted that late complications of radiotherapy are poorly recorded in these phase III trials, as more uniform scores specifically addressed to radiation therapy toxicity were not available at the time of these trials, and also because acute toxicity could not be directly compared as different scoring systems were used. Looking at larger BRT studies, Chapet et al. [10] reported $60 \%$ of radiationinduced acute toxicity, mainly G2 painful perineal skin, while the other two studies did not give data on acute toxicity $[9,11]$. Concerning late toxicity, and particularly anorectal toxicity, 13 of 286 patients underwent colostomy for G4 toxicity in the study of Tournier-Rangeard et al., but they did not report the rate of colostomy in the two groups of boost technique delivery (EBRT, 24 patients vs. BRT, 233 patients) [11]. Chapet et al. reported a global rate of late G3-G4 toxicity of $23.4 \%$, with 13 of 221 patients $(5.8 \%)$ undergoing colostomy because of treatment-related toxicity [10]. In the study of Papillon et al. [9], G3G4 late complications were uncommon, with seven of 221 cases (3.1\%) of colostomy. These authors underlined the importance of strictly following the BRT procedure and, in particular, the importance of maintaining an intersource spacing greater than $1.5 \mathrm{~cm}$. These results are similar to our rates of G3-G4 late toxicity (6.2\%) and toxicity-related colostomy (6/219 patients, $2.8 \%$ ). The results of the particular subgroup of T3-T4 patients should also be discussed: Generally, T4 anal canal tumors are not considered good candidates for BRT, because of the high risk of toxicity, as they usually require many more needles. In our experience, we treated five patients with T4 disease, three after a major response to RT-CT and two young patients (52 and 57 years old) refusing surgery. Four of these five patients are disease-free after at least 36 months post-BRT. This population is obviously too small to draw any conclusion about the potential value of BRT in this clinical setting, but it could be interesting to evaluate it, in particular for patients presenting with a major response after RT-CT.

Univariate analysis did not show technical BRT-related variables statistically influencing the risk of late G3-G4 toxicity. In the only study specifically addressed to BRT toxicity, the total dose of BRT and the total delivered dose $(\mathrm{EBRT} \pm \mathrm{CT}$ and BRT) statistically increased the rate of toxicity [25]. Our study confirms the significant impact of total dose on the risk of late severe toxicities. By contrast, Touboul et al. did not did not confirm this association [29].

The problem about the optimal technique for delivering boost (EBRT vs. BRT) is not solved, as a direct relationship between BRT and anorectal severe late toxicity has never been clearly proven.

It should benoted that patients in all the larger studies, except for some patients in the study of Tournier-Rangeard et al., 
were treated with 2D-EBRT. The promising impact of the routine use of 3D- with IMRT techniques and, more recently, of volumetric arc and helical EBRT as well as image-guided EBRT has not been extensively explored. The potential clinical benefits of the dosimetric advantages of these techniques in the treatment of anal canal cancer patients should be prospectively evaluated $[30,31]$.

Moreover, the introduction of new BRT techniques, such as high-dose rate BRT (HDR-BRT), with or without modern EBRT $\pm \mathrm{CT}$, raises other clinical and technical issues that need to be prospectively analyzed: An interesting study by Saarilahti et al., combining IMRT and HDR-BRT for the treatment of anal canal cancer patients, showed that "...IMRT significantly reduces acute radiotherapyassociated adverse events in patients treated by chemoradiotherapy for anal cancer. A combination of external radiotherapy and HDR brachytherapy may reduce the risk of late radiation proctitis..." [32].

In the era of tailored oncologic treatments, reflection is needed to assess the optimal treatment approach. As already suggested by Chapet et al. and by Tournier-Rangeard et al., EBRT \pm CT and BRT should probably be preferred in the treatment of localized tumors, while a more aggressive approach, which could also integrate surgery for poorly responding patients, should be considered for locally advanced cancers. Knowledge of the risks of toxicity and disease relapse would help clinicians in their decision-making process.

\section{Conclusion}

This long-term analysis of a large population of patients with anal canal cancer confirms that BRT is safe and effective in the treatment of these patients. Our data indicate that a dose greater than $63 \mathrm{~Gy}$ does not improve the clinical outcomes of the patients, but it seems to be statistically more toxic. The role of BRT in the treatment of more advanced but well-responding tumors should be further investigated. Prospective studies are needed to assess better its role in the multidisciplinary and tailored approach to this disease.

\section{Corresponding address}

\section{B. De Bari MD}

Radiation Oncology, Centre hospitalier

universitaire vaudois (CHUV)

Rue du Bugnon 46, 1011 Lausanne

bdebari@yahoo.it

\section{Compliance with ethical guidelines}

Conflict of interest. L. Lestrade, B. De Bari, P. Pommier, X. Montbarbon, E. Lavergne, J.-M. Ardiet, and C. Carrie state that there are no conflicts of interest.

\section{References}

1. Williams M, Swampillai A, Osborne M et al Mount Vernon Colorectal Cancer Network (2013) Squamous cell carcinoma antigen: a potentially useful prognostic marker in squamous cell carcinoma of the anal canal and margin. Cancer 119:2391-2398

2. No authors listed (1996) Epidermoid anal cancer: results from the UKCCCR randomised trial of radiotherapy alone versus radiotherapy, 5-fluorouracil, and mitomycin. UKCCCR Anal Cancer Trial Working Party. UK Co-ordinating Committee on Cancer Research. Lancet 348:1049-1054

3. Bartelink H, Roelofsen F, Eschwege F et al (1997) Concomitant radiotherapy and chemotherapy is superior to radiotherapy alone in the treatment of locally advanced anal cancer: results of a phase III randomized trial of the European organization for research and treatment of cancer radiotherapy and gastrointestinal cooperative groups. J Clin Oncol 15:2040-2049

4. Flam M, John M, Pajak TF et al (1996) Role of mitomycin in combination with fluorouracil and radiotherapy, and of salvage chemoradiation in the definitive nonsurgical treatment of epidermoid carcinoma of the anal canal: results of a phase III randomized intergroup study. J Clin Oncol 14:25272539

5. Ferrigno R, Nakamura RA, Dos Santos Novaes PE et al (2005) Radiochemotherapy in the conservative treatment of anal canal carcinoma: retrospective analysis of results and radiation dose effectiveness. Int J Radiat Oncol Biol Phys 61:1136-1142

6. Huang K, Haas-Kogan D, Weinberg V et al (2007) Higher radiation dose with a shorter treatment duration improves outcome for locally advanced carcinoma of anal canal. World J Gastroenterol 13:895-900

7. National Comprehensive Cancer Network (2014) http://www.nccn.org/professionals/physician_ gls/f_guidelines.asp\#anal. Accessed 22 Dec. 2013

8. Gerbaulet A, Pötter R, Mazeron JJ et al (2002) The GEC ESTRO Handbook of Brachytherapy (ISBN 90 804532-6). Bruxelles, pp. 505-514. (The Authors and ESTRO)

9. Papillon J, Montbarbon JF, Gerard JP et al (1989) Interstitial curietherapy in the conservative treatment of anal and rectal cancers. Int J Radiat Oncol Biol Phys 17:1161-1169

10. Chapet O, Gerard JP, Riche B et al (2005) Prognostic value of tumor regression evaluated after first course of radiotherapy for anal canal cancer. Int J Radiat Oncol Biol Phys 63:1316-1324
11. Tournier-Rangeard L, Peiffert D, Lafond $C$ et al (2007) Long-term results and prognostic factors of squamous cell carcinoma of the anal canal treated by irradiation. Cancer Radiother 11:169-177

12. Sobin LH, Gospodarowicz MK, Wittekind Ch (Eds) (2009) TNM classification of malignant tumors, 7th edn. Wiley-Blackwell, Oxford . (ISBN 978-1-44433241-4)

13. National Cancer Institute (2009) Common Terminology Criteria for Adverse Events (CTCAE), version 4.0. Available via http://evs.nci.nih.gov/ftp1/ CTCAE/CTCAE_4.03_2010-06-14_QuickReference_5×7.pdf. Accessed 22 Dec. 2013

14. Womack NR, Morrison JF, Williams NS (1988) Prospective study of the effects of postanal repair in neurogenic faecal incontinence. $\mathrm{Br} J$ Surg 75:48-52

15. De Bari B, Bosset JF, Gérard JP et al (2012) Evidences in multidisciplinary management of rectal cancer. Cancer Radiother 16:711-720

16. Aggarwal A, Gayadeen S, Robinson D et al (2012) Clinical target volumes in anal cancer: calculating what dose was likely to have been delivered in the UK ACT II trial protocol. Radiother Oncol 103:341-346

17. Nieder C (2013) Concurrent radiochemotherapy with 5 -FU/mitomycin remains standard treatment for anal carcinoma. Long-term results of the phase III RTOG 98-11 trial. Strahlenther Onkol 189:512-513

18. Zilli T, Schick U, Ozsahin M et al (2012) Node-negative T1-T2 anal cancer: radiotherapy alone or concomitant chemoradiotherapy? Radiother Oncol 102:62-67

19. Lestrade L, De Bari B, Montbarbon X et al (2013) Radiochemotherapy and brachytherapy could be the standard treatment of anal canal cancer in elderly patients? A retrospective single centre analysis. Med Oncol 30:402

20. De Bari B, Lestrade L, Chekrine T et al (2012) Should the treatment of anal carcinoma be adapted in the elderly? A retrospective analysis of acute toxicities in a French centre and a review of the literature (in French). Cancer Radiother 16:52-57

21. Fraunholz I, Rabeneck D, Gerstein J et al (2011) Concurrent chemoradiotherapy with 5-fluorouracil and mitomycin C for anal carcinoma: are there differences between HIV-positive and HIV-negative patients in the era of highly active antiretroviral therapy? Radiother Oncol 98:99-104

22. Fraass BA, Moran JM (2012) Quality, technology and outcomes: evolution and evaluation of new treatments and/or new technology. Semin Radiat Oncol 22:3-10. (Review)

23. Valentini V, Bourhis J, Hollywood D (2012) ESTRO 2012 strategy meeting: vision for radiation oncology. Radiother Oncol 103:99-102

24. Reddy S, Lee MS, Bonomi P et al (1994) Radiation therapy in the conservative treatment of carcinoma of the anal canal. Int J Radiat Oncol Biol Phys 29:17-23

25. Peiffert D, Bey P, Pernot M et al (1997) Conservative treatment by irradiation of epidermoid cancers of the anal canal: prognostic factors of tumoral control and complications. Int J Radiat Oncol Biol Phys 37:313-324

26. Weber DC, Kurtz JM, Allal AS (2001) The impact of gap duration on local control in anal canal carcinoma treated by split-course radiotherapy and concomitant chemotherapy. Int J Radiat Oncol Biol Phys 50:675-680 
27. Engineer R, Mallik S, Mahantshetty U et al (2010) Impact of radiation dose on locoregional control and survival on squamous cell carcinoma of anal canal. Radiother Oncol 95:283-287

28. Widder J, Kastenberger R, Fercher E et al (2008) Radiation dose associated with local control in advanced anal cancer: retrospective analysis of 129 patients. Radiother Oncol 87:367-375

29. Touboul E, Schlienger M, Buffat L et al (1994) Epidermoid carcinoma of the anal canal. Results of curative-intent radiation therapy in a series of 270 patients. Cancer 73:1569-1579

30. Dewas CV, Maingon P, Dalban C et al (2012) Does gap-free intensity modulated chemoradiation therapy provide a greater clinical benefit than $3 D$ conformal chemoradiation in patients with anal cancer? Radiat Oncol 7:201

31. Brooks CJ, Lee YK, Aitken K et al (2013) Organ-sparing intensity-modulated radiotherapy for anal cancer using the actii schedule: a comparison of conventional and intensity-modulated radiotherapy plans. Clin Oncol (R Coll Radiol) 25:155-61

32. Saarilahti K, Arponen P, Vaalavirta L et al (2008) The effect of intensity-modulated radiotherapy and high dose rate brachytherapy on acute and late radiotherapy-related adverse events following chemoradiotherapy of anal cancer. Radiother Oncol 87:383-390 